\title{
High performance piezoelectric AIN MEMS resonators for precise sensing in liquids
}

\author{
M. Schneider, G. Pfusterschmied, F. Patocka, U. Schmid
}

\begin{abstract}
Piezoelectric silicon micro-machined resonators triggered in the two-dimensional roof-tile shaped mode exhibit exceptionally high quality factors even in highly viscous liquids. In combination with an all-electric readout, this enables precise measurements in liquid media with high output signals, if the electrode design and the anchor geometry are tailored to match the selected order of the rooftile shaped mode. This paper provides an overview of this promising class of resonator modes for micro-electromechanical systems (MEMS) and highlights three application scenarios. In the food industry, the MEMS sensor can be used to monitor the fermentation process in wine by tracking the density and hence, the concentration of ethanol. In technical lubricants, the concentration of ferrous particles can be monitored by integrating a magnetic actuator on the resonator. Finally, even in highly viscous bitumen, the MEMS sensor is successfully used to measure the viscosity of this material.
\end{abstract}

Keywords: liquid sensing; MEMS; resonators; piezoelectric; realtime monitoring

Piezoelektrische AIN-basierte MEMS-Resonatoren für hochgenaue Messungen in Flüssigkeiten.

Piezoelektrische, durch Mikrofabrikation hergestellte Siliziumresonatoren, die in 2D-„Wellblech"-Schwingungsmoden angeregt werden, weisen selbst in hochviskosen Flüssigkeiten außergewöhnlich hohe Qualitätsfaktoren auf. In Kombination mit einer vollständig elektrischen Anregung und Auslesung ermöglicht dies präzise Messungen in flüssigen Medien mit hohen Ausgangssignalen, wenn das Elektrodendesign und die Ankergeometrie auf die ausgewählte Ordnung der "Wellblech"-Mode abgestimmt sind. Dieser Artikel bietet einen Überblick über diese vielversprechende Klasse von Resonatormoden für mikroelektromechanische Systeme (MEMS) und zeigt drei Anwendungsszenarien auf. In der Lebensmittelindustrie kann der MEMS-Sensor verwendet werden, um den Fermentationsprozess in Wein durch Verfolgung der Dichte und damit der Ethanolkonzentration zu überwachen. In technischen Schmierstoffen kann die Konzentration von Eisenpartikeln durch Integration eines magnetischen Aktuators auf dem Resonator überwacht werden. Abschließend kann der MEMS-Sensor auch in hochviskosem Bitumen erfolgreich zur Messung der Viskosität dieses Materials eingesetzt werden.

Schlüsselwörter: Flüssigkeitssensorik; MEMS; Resonatoren; piezoelektrisch; Echtzeit-Überwachung

Received January 30, 2020, accepted March 30, 2020, published online April 8, 2020

(c) The Author(s) 2020

\section{Introduction}

Micro electromechanical systems (MEMS) based resonator sensors are utilized in a wide variety of fields to detect both physical and chemical quantities. This includes the sensing of density and viscosity in liquids [1-3], pressure sensing in gases [4,5] and the sensing of mass changes when used as micro balance for the detection of chemical and biological agents [6-11]. Of the various types of resonator geometries (strings, membranes, etc.), cantilever based devices have attracted much attention due to the low impact of residual stress on key device parameters like the resonance frequency. Cantilever modes are into different basic types of mode shapes: transversal, torsional, extensional and lateral.

Transversal or out-of-plane modes are primarily used for atomic force microscopy and micro balance applications [9, 12]. When comparing the performance of these modes in liquids, it was found, that the quality factor, which is in liquids primarily linked to viscous damping, does not exceed 35 [9]. This is a limitation when going into liquids with higher viscosity, as the increased damping will not allow any oscillation of the resonator to occur. To overcome this drawback to at least some degree, lateral or in-plane modes can be used, which can reach quality factors between 65 and 100 in water $[9,13,14]$.
This paper will give an overview over a MEMS based piezoelectric sensor platform developed at ISAS, TU Wien. ${ }^{1}$ This sensor platform utilizes a novel type of resonator mode, which features unprecedented quality factors in water of up to 366 for higher mode orders. As a consequence, measurements not just in water, but also in highly viscous liquids like lubrication oil, or even bitumen are enabled. The devices presented in this paper are all based on this sensor platform, the design however varies depending on the application.

\section{Methods}

\subsection{Sensor design and fabrication}

The sensor fabrication process starts with a 4 inch silicon on insulator (SOI) wafer with a typical device layer thickness of $20 \mu \mathrm{m}$.

${ }^{1} \mathrm{https}: / / \mathrm{mst}$.isas.tuwien.ac.at.

Schneider, Michael, Institute of Sensor and Actuator Systems, TU Wien, Gusshausstraße 27-29, A-1040 Vienna, Austria (E-mail: michael.schneider@tuwien.ac.at);

Pfusterschmied, Georg, Institute of Sensor and Actuator Systems, TU Wien, Gusshausstraße 27-29, A-1040 Vienna, Austria; Patocka, Florian, Institute of Sensor and Actuator Systems, TU Wien, Gusshausstraße 27-29, A-1040 Vienna, Austria; Schmid, Ulrich, Institute of Sensor and Actuator Systems, TU Wien, Gusshausstraße 27-29, A-1040 Vienna, Austria 


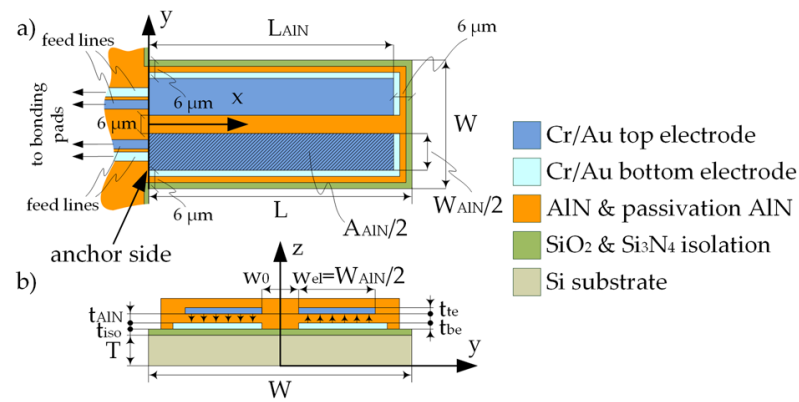

Fig. 1. Schematics of the typical cantilever architecture. (a) Top view (b) cross-sectional view, including a visualization of the electrical field. Reprinted from [15], @2014 with permission from Elsevier

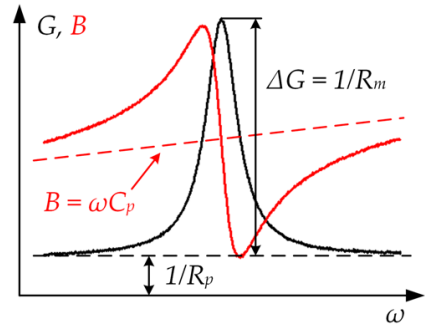

Fig. 2. Visualization of the real $(G)$ and imaginary $(B)$ part of the admittance $Y$ including parasitic effects $\left(R_{p}, C_{p}\right)$. Reprinted from [15], ○2014 with permission from Elsevier

The wafer is covered by a bi-layer of $250 \mathrm{~nm}$ thermal oxide and $80 \mathrm{~nm}$ LPCVD silicon nitride to ensure electrical isolation of the bottom electrodes. These electrodes are deposited using evaporation and patterned via a lift-off procedure. Subsequently, the piezoelectric layer of aluminum nitride (AIN) is deposited using reactive magnetron sputtering and the top electrode is realized in the same way as the bottom electrodes. The device is defined by a top side deep reactive ion etch (DRIE) step and released by a backside DRIE step followed by the removal of the buried oxide by hydrofluoric acid.

A typical device geometry with two electrode stripes is shown in Fig. 1. The finished devices are placed in dual inline packages and wire bonded. More details can be found in $[15,16]$.

\subsection{Sensor characterization and measurement}

A Butterworth-van Dyke equivalent circuit consisting of a parallel connection of a resistor $\left(R_{\mathrm{p}}\right)$, a capacitor $\left(C_{\mathrm{p}}\right)$ and a LCR circuit $\left(R_{\mathrm{m}}, C_{\mathrm{m}}\right.$ and $\left.L_{\mathrm{m}}\right)$ is used to describe the electrical characteristics of the MEMS resonator. $R_{\mathrm{p}}$ and $C_{\mathrm{p}}$ represent the static AIN capacitor, whereas $R_{\mathrm{m}}, C_{\mathrm{m}}$ and $L_{\mathrm{m}}$ model the electrical signal of the mechanical resonance. Figure 2 shows the typical spectra of the conductance $G$ and the susceptance $B$ of the MEMS resonator. The static conductance is given by $1 / R_{\mathrm{p}}$ and is increased by $\Delta G=1 / R_{\mathrm{m}}$ in resonance. The quality factor $Q$ is calculated from the circuit parameters by the well-known equation $Q=1 / R_{m} \sqrt{L_{m} / C_{m}}$ or by fitting the susceptance minimum and maximum.

In order to obtain a high measurement signal, it is important to maximize $\Delta G$ and to minimize $1 / R_{\mathrm{p}}$. This can be challenging especially in liquids, as the high damping will reduce the quality factor and hence, $\Delta G$. A more detailed description of the mathematical modelling approach of the resonator can be found in [15].

Electrical measurements of the MEMS resonators both in air and in liquids are done with an Agilent 4294A impedance analyzer under controlled temperature conditions. Optical measurements of the
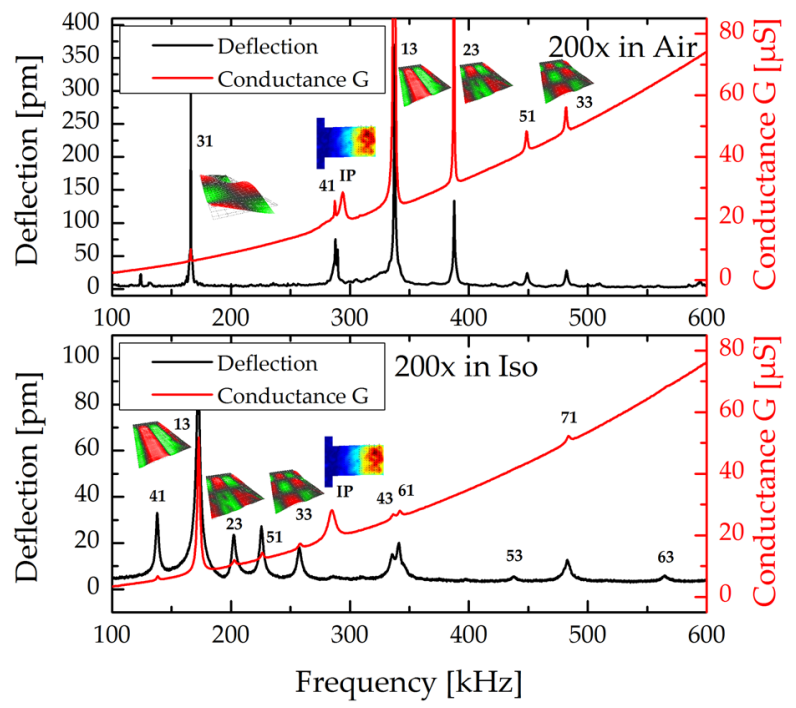

Fig. 3. Frequency spectra of the MEMS resonator in air and in iso-propanol. The plots show the out-of-plane (left axis, lower curve) as well as the conductance spectrum (right axis, upper curve). [15], @2014 with permission from Elsevier

out-of-plane movement are performed with a Polytec MSA 400 laser Doppler vibrometry system. Density $\rho$ and dynamic viscosity $\mu$ of the investigated liquids are measured with a Stabinger SVM 3000 viscometer at defined temperatures. The test liquids included deionized water, ethanol, isopropanol, D5, N10, N35, N100, S200 and D500. Doing so, dynamic viscosity at room temperature were varied up to $615 \mathrm{mPas}$ [17]. Vibrational modes are specified using the notation by Leissa ${ }^{2}[18]$.

\section{Results}

The following sections will present a short overview of the most important results achieved with the AIN MEMS resonator sensor platform developed at ISAS.

\subsection{Roof-tile shaped modes}

Figure 3 shows both optical and electrical spectra of a $2017 \mu \mathrm{m} \times$ $1272 \mu \mathrm{m}$ cantilever resonator in both air and isopropanol with the corresponding mode shapes for each resonance. The high damping of most resonance modes is clearly visible; however, one mode shape features high quality factors independent of the environmental conditions, labeled as 13 mode. This mode shape is representative for a new class of torsional type modes: the roof-tile shaped modes. Subsequent studies using the same sensor design approach confirmed this result and demonstrated high quality factors for the 12 mode of 10 in highly viscous liquids like D500. Furthermore, a direct correlation between the quality factor and $1 / \sqrt{\rho \mu}$ was found, which shows the potential for this sensor to measure both the density and dynamic viscosity of liquids [17]

By increasing the drive frequency, higher orders of the 12 mode can be excited. The impact on the quality factor in deionized water is shown up to the 10th order in Fig. 4. Hexadecimal numbering is used for the Leissa nomenclature. The insets show the corresponding mode shape and the dashed line represents viscous damping deduced from theoretical considerations where the cantilever is

${ }^{2}$ Note number of nodal lines in $\mathrm{x}$ and $\mathrm{y}$ direction by two numbers according to axis given in Fig. 1. 


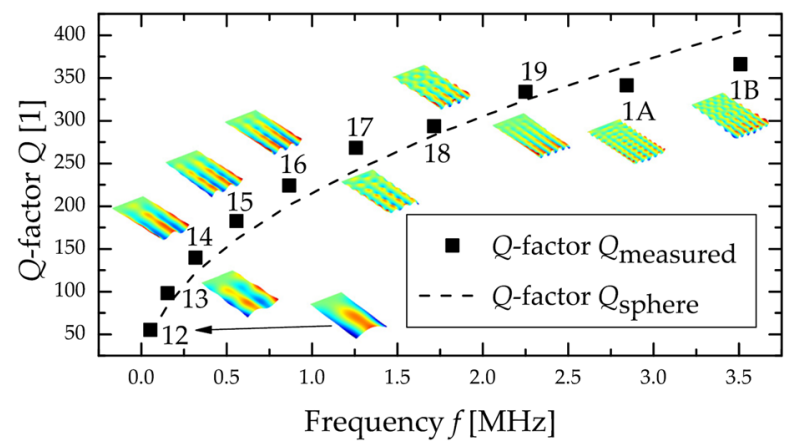

Fig. 4. Q-factors of different multi roof tile-shaped modes as a function of resonance frequency in deionized water. The small insets represent the mode shapes under study derived from FEM simulations. Reprinted with permission from [19], @2015 AIP Publishing LLC

Table 1. Performance of the higher orders of the roof tile-shaped modes in deionized water. Due to its high order, hexadecimal numbers are used for the labelling. Reprinted with permission from [19] @2015 AIP Publishing LLC

\begin{tabular}{lllll}
\hline Order & Mode & $f_{\text {res }}[\mathrm{kHz}]$ & $Q[1]$ & $\Delta G[\mu \mathrm{S}]$ \\
\hline 1 & 12 & 53.49 & 55.2 & 6.95 \\
2 & 13 & 152.43 & 98.1 & 77.61 \\
3 & 14 & 317.30 & 139.8 & 54.94 \\
4 & 15 & 555.93 & 182.7 & 9.45 \\
5 & 16 & 866.53 & 224 & 101.60 \\
6 & 17 & 1256.64 & 268.3 & 328.37 \\
7 & 18 & 1714.17 & 293.3 & 158.48 \\
8 & 19 & 2250.98 & 333.9 & 24.81 \\
9 & $1 \mathrm{~A}$ & 2842.84 & 341.4 & 149.67 \\
10 & $1 \mathrm{~B}$ & 3508.69 & 366.2 & 443.37 \\
\hline
\end{tabular}

approximated by a sphere to enable an analytically solution of the Navier-Stokes equations [19]. The corresponding results for the resonance frequency $f_{\text {res, }} Q$ and $\Delta G$ are given in Table 1. A quality factor of 366 was measured for the $1 \mathrm{~B}$ mode in water at a frequency of 3.5 MHz, which was the highest value measured up to that time for cantilever type resonators in liquid media. While $Q$ continuously increases with increasing $f_{\text {res }}, \Delta G$ does not feature a clear trend. This is due to the fact, that the electrode design can act as a filter for higher modes due to partial or complete cancelation of charges, if the electrode covers areas with both positive and negative volume strains [20]. It is therefore necessary to tailor the electrode design.

\subsection{Electrode and anchor optimization}

The roof-tile shaped modes in cantilever type resonators generally feature only a single nodal line along the x-axis (the anchor) and multiple nodal lines along the $y$-axis. This enables an optimized electrode design (OED) by using multiple electrode stripes perpendicular to the anchor nodal line, which simplifies the electrical feed lines significantly.

To increase device performance, effort was invested in a tailored mode specific anchor design by moving from a single side clamped cantilever type resonator to a double side clamped bridge type resonator. Compared to a typical bridge design, the resonating plate is only fixed at the nodal lines, which minimizes the anchor strain and basically results in a design mimicking the mathematical free-free boundary condition best. The results for these resonators in liquids

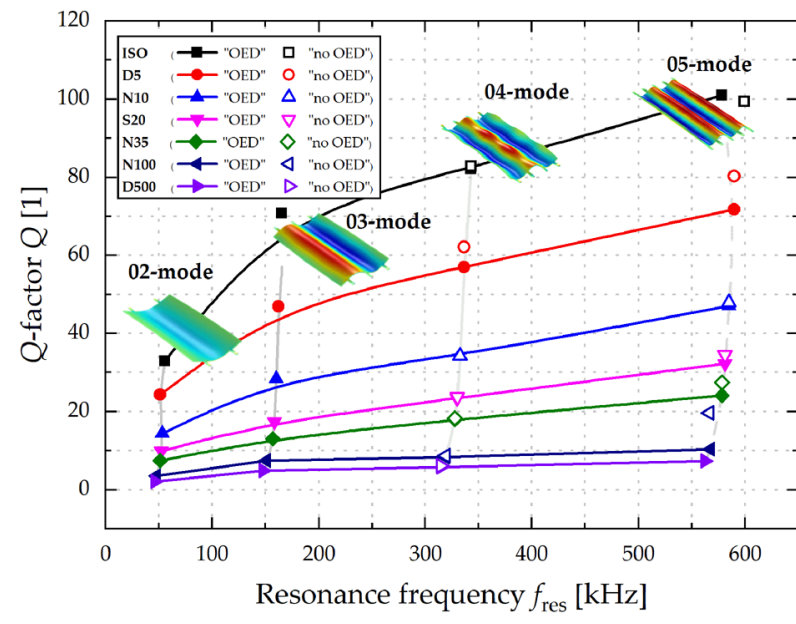

Fig. 5. Q-factors of the OX-modes with and without OED in different liquids. Reprinted from [21], @2016 with permission from Elsevier

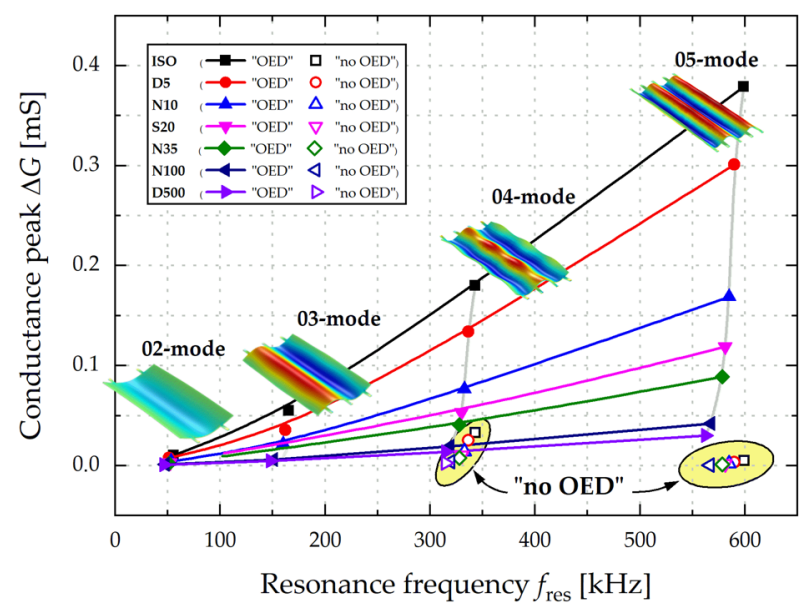

Fig. 6. Electrical characterization of the $0 \mathrm{X}$-modes with and without OED in different liquids represented by the conductance peak $\Delta \mathrm{G}$ as a function of the resonance frequency. Reprinted from [21], @2016 with permission from Elsevier

with respect to $Q$ are shown in Fig. 5 and for $\Delta G$ in Fig. 6, respectively. The quality factor increases as expected with increasing mode order and decreases with increasing $1 / \sqrt{\rho \mu}$. An impact of OED on $Q$ was not observed. $\Delta G$ on the other hand was significantly improved by OED. The highest value $\Delta G=379 \mu \mathrm{S}$ was measured for the 05 mode in isopropanol. Compared to the result without OED, this corresponds to an improvement by a factor of 77 and demonstrates the importance of OED.

\subsection{Applications}

The fermentation of grape must into wine involves yeasts, which convert sugars in the must into ethanol. During this process, it is possible for the yeasts to stop growing and not produce ethanol any longer. This is referred to as stuck fermentation and poses a serious problem in wine making, if not detected at an early stage. The different ethanol concentrations in normal and stuck states of fermentation results in a slight variation of the density of the grape must and can thus be detected by the presented MEMS resonator sensor, shown in Fig. 7. 


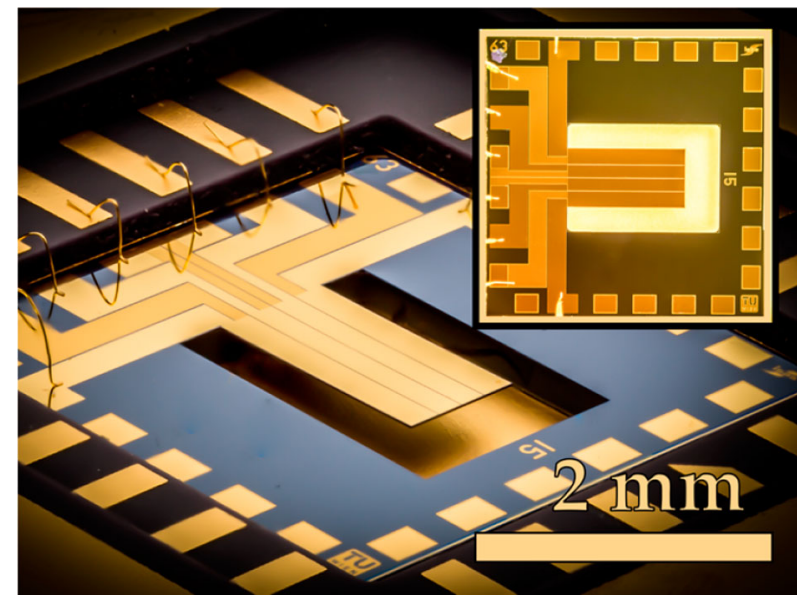

Fig. 7. Optical micrograph of the silicon die $(6 \mathrm{~mm} \times 6 \mathrm{~mm})$ fabricated at ISAS, TU Wien. The electrode patterning is matched to the modal shape of the resonator. Reprinted from [22] under CC BY 4.0

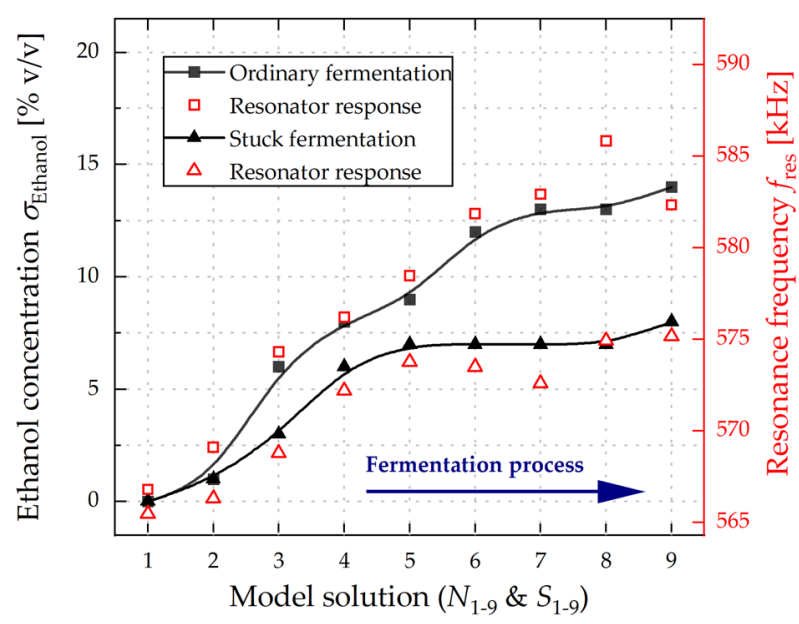

Fig. 8. 15-mode frequency response analysis of ordinary $\left(\boldsymbol{N}_{1-9}\right)$ and stuck $\left(S_{1-9}\right)$ fermentation process in comparison to the nominal ethanol concentration of the investigated model solutions. Reprinted from [22] under CC BY 4.0

For this application, the sensor in the package is fully coated by a $4 \mu \mathrm{m}$ thick amorphous silicon dioxide film to eliminate any parasitic leakage currents through the grape must, which would result in a lower $R_{\mathrm{p}}$ value. The sensor is operated in the 15 -mode and tested in model solutions $N_{1-9}$ and $S_{1-9}$, which represent both normal and stuck fermentation stages [22]. The resonance frequency and quality factor are measured and used to calculate the density of the liquid according to $[22,23]$.

Figure 8 shows both the ethanol concentration and the resonance frequency for normal as well as stuck fermentation. It is clearly visible, that the ethanol concentration deviates from the normal fermentation characteristics already at an early stage of the process. In addition, an excellent correlation between $f_{\text {res }}$ and the ethanol concentration is observed.

Figure 9 shows the density variation with continuous fermentation, measured with both the MEMS sensor and a Stabinger viscometer. The results of the bulky, table-top sized Stabinger lab equipment are in excellent agreement with those from the MEMS sensor. This also demonstrates, that it is possible to distinguish be-

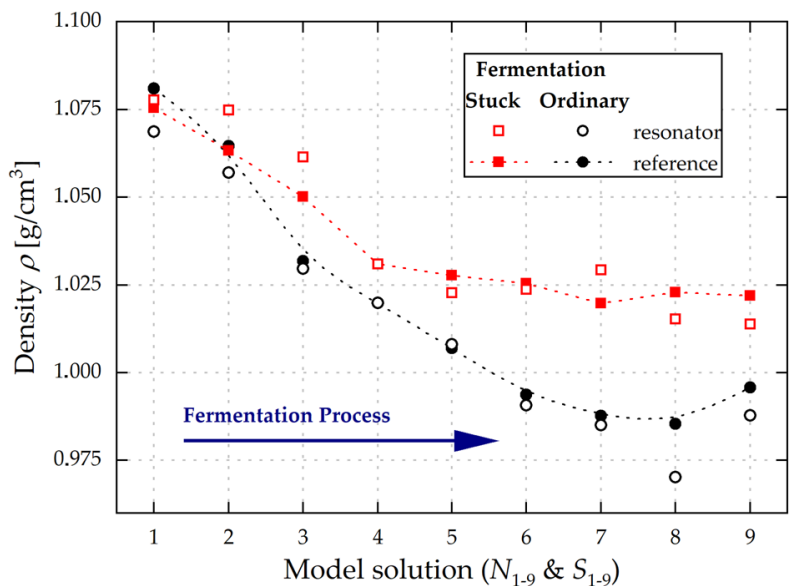

Fig. 9. Density values for ordinary $\left(\boldsymbol{N}_{1-9}\right)$ and stuck $\left(\boldsymbol{S}_{1-9}\right)$ fermentation model solutions determined with the MEMS resonator and a Stabinger SVM3000 viscometer. Reprinted from [22] under CC BY 4.0

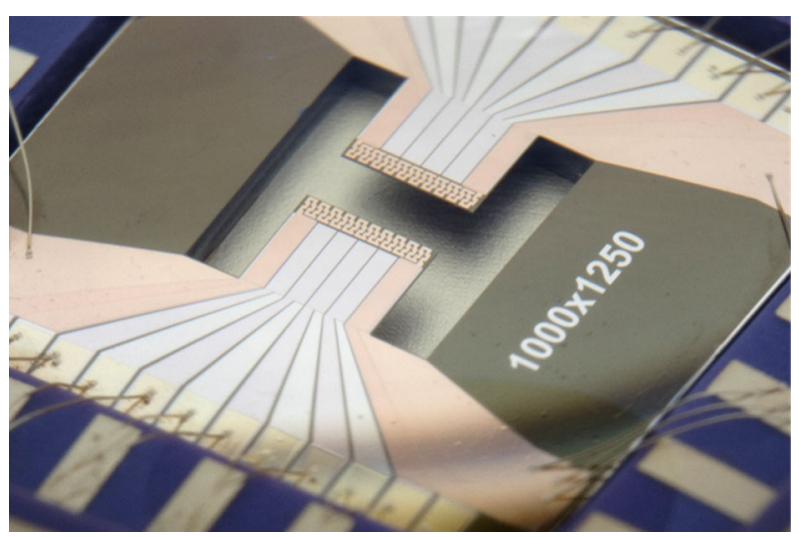

Fig. 10. Optical micrograph of the MEMS sensor, consisting of two identical micro cantilevers with planar coils integrated close to the free ends. Reprinted from [24], @2019 with permission from Elsevier

tween the normal and stuck fermentation branch at a very early stage during the fermentation process with an integrated MEMS sensor approach.

Similar measurements were performed on Airen grape must after a filtering process to remove large grape skin particles. The monitoring is done ex-situ on samples taken every 5 hours after centrifugation. A shift in the resonance frequency comparable to Fig. 8 is observed, demonstrating that this sensor system has the potential to monitor even this complex biological process precisely compared to state of the art equipment.

In the above mentioned lab experiment, any particles are removed to avoid contamination of the sensor. In technical liquids like lubrication oils on the other hand, the detection of particles is of high interest as the amount of such particles gives a direct indication with respect to the wear in the mechanical components such as pumps, of a hydraulic system. Since most machine parts are made of steel, the most prominent type of wear particle is ferrous debris.

In order to detect such particles efficiently with the MEMS resonator sensor developed at ISAS, it is necessary to actively attract those ferrous particles to the sensor surface. This is done by a planar coil, which is placed close to the tip of the cantilever type resonator and loaded with a current of $150 \mathrm{~mA}$. Note, that this coil is realized as part of the microfabrication process of the sensor. The final sensor is shown in Fig. 10. 

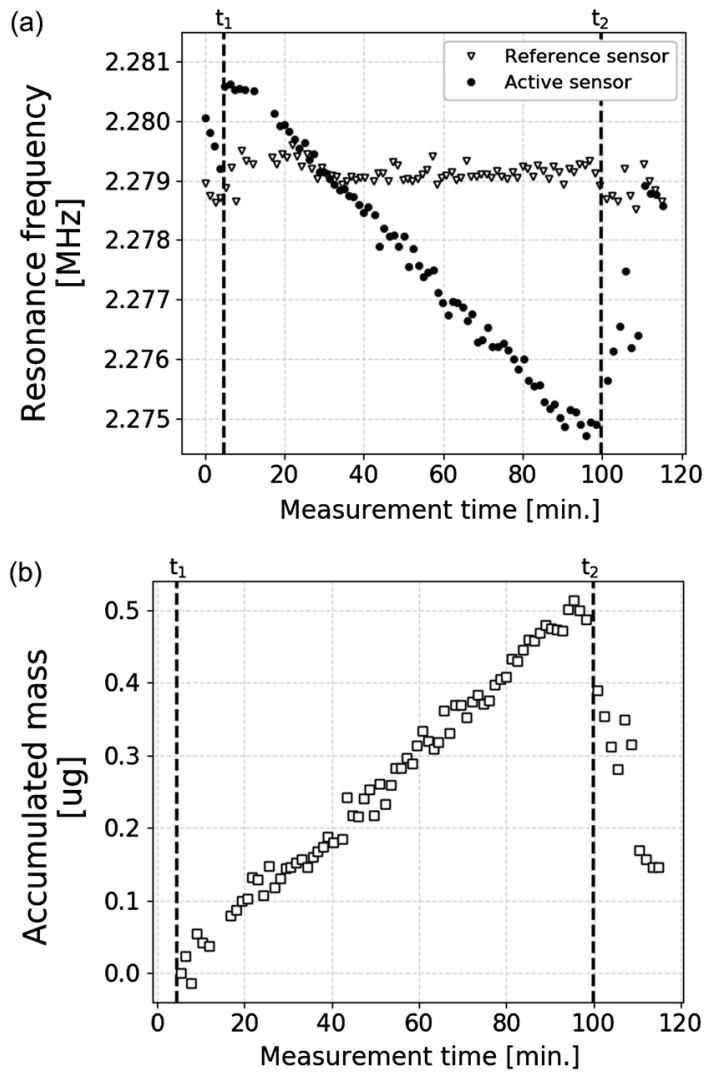

Fig. 11. (a) Resonance frequency of the active and reference cantilever in water. The accumulation of ferrous particles starts at $t_{1}$. At $t_{2}$ the accumulation stops and the sensor is rinsed with fresh deionized water. (b) Accumulated particle mass during the experiment. Reprinted from [24], @2019 with permission from Elsevier

The added mass of the ferrous particles $\Delta m$ will shift the resonance frequency according to

$$
\Delta f=-\frac{1}{2} \frac{\Delta m}{M} f_{\text {res }} \phi^{2}\left(x_{\Delta m}, y_{\Delta m}\right) .
$$

$M$ is the total oscillation mass and $\phi\left(x_{\Delta m}, y_{\Delta m}\right)$ is the value of the mode shape function at the position of the mass [24]. The mode shape function describes the position dependence of the shift in $f_{\text {res }}$ due to particle-related mass loading. Regions with high displacement amplitudes will be significantly more responsive compared to those with low amplitude (i.e. the nodal lines). The coil is designed to mainly attract particles in regions with high responsivity to maximize the overall performance of the sensor.

The MEMS device is tested in a model solution of deionized water and dispersed iron oxide $\left(\mathrm{Fe}_{3} \mathrm{O}_{4}\right)$ nanoparticles with a hydrodynamic diameter of $250 \mathrm{~nm}$ and a final concentration of $350 \mu \mathrm{g} / \mathrm{ml}$. To compensate for any parasitic sensor drift due to temperature or unintended sedimentation, a pair of cantilever sensors is used with only one coil active, enabling a differential measurement approach (see Fig. 10). The resonance spectrum is fitted by the phase function, which allowed an accuracy in the determination of $f_{\text {res }}$ of $50 \mathrm{~Hz}$. The results of this study are shown in Fig. 11.

The coil is current loaded at the time $t_{1}$. The instant increase in $f_{\text {res }}$ can be attributed to current induced heating. A steady decrease of $f_{\text {res }}$ is then observed over a period of 100 min., as ferrous particles are collected and the sensor mass is increased. Note, that the reference sensor provides a stable output characteristic as a function of time.

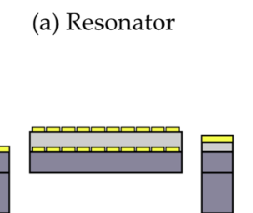

(c) Annealing process @ $100^{\circ} \mathrm{C}$

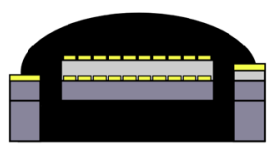

(b) Bitumen placement

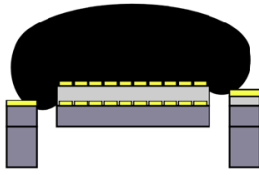

(d) Sensing procedure

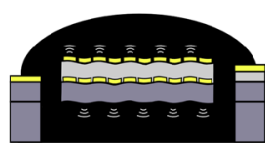

Si

$\mathrm{Ti}$ $\mathrm{Cr} / \mathrm{Au}$ $\square$ AIN Bitumen

Fig. 12. Schematic illustration of the measurement procedure, represented by cross-sectional views of the resonator. In (a), the bare resonator is depicted. About $100 \mu \mathrm{l}$ bitumen is placed on top of the resonator as shown in $(b)$. In the following annealing process (c), the bitumen penetrates into the cavity and the resonator is then excited as shown in (d). @2019 IEEE. Reprinted, with permission, from [25]

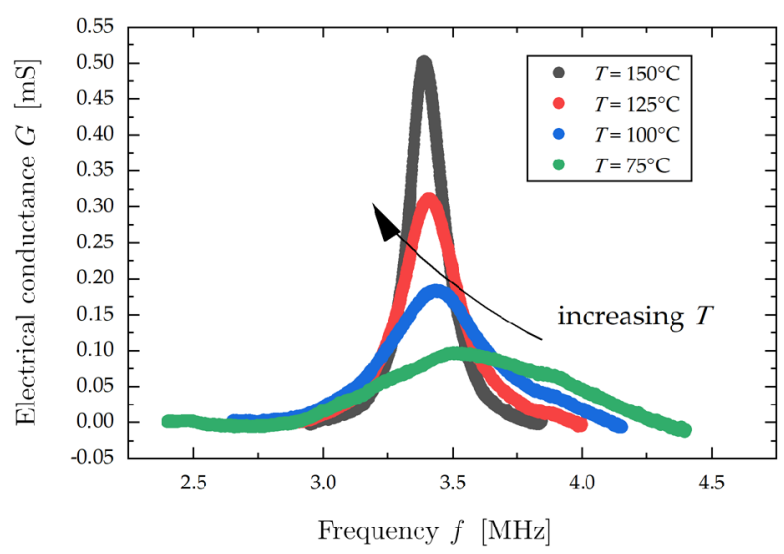

Fig. 13. Frequency response characteristics of the electrical conductance $G$ of the piezoelectric MEMS resonator, when immersed in the bitumen derivative $B 3$ at different temperatures $(T=75,100,125$ and $150^{\circ} \mathrm{C}$ ). $\odot 2019$ IEEE. Reprinted, with permission, from [25]

Using Eq. (1) and integrating over the cantilever surface yields the total accumulated mass as shown in Fig. 11b). After 100 min., the total mass is about $0.49 \mu \mathrm{g}$, which corresponds to a mass responsivity of $82.85 \mathrm{pg} / \mathrm{Hz}$. Given the accuracy of $f_{\text {res }}$ with $50 \mathrm{~Hz}$, this results in a limit of detection for this sensor of $4 \mathrm{ng}$. The high responsivity is impressive for a sensor design of this size, since approaches with similar responsivities typically utilize much smaller sensor geometries $[24,26,27]$.

Finally, the outstanding performance in terms of quality factors can be utilized to even measure the viscosity of extremely viscous materials like bitumen. For this purpose, bitumen is heated up to $100^{\circ} \mathrm{C}$, placed on the MEMS sensor and annealed for $10 \mathrm{~min}$. to ensure complete sensor coverage as shown in Fig. 12. The bitumen covered sensor is then placed into a Vötsch VCL4006 climate chamber to perform impedance spectroscopy in a temperature range between 75 and $150^{\circ} \mathrm{C}$. A Lorentzian is fitted to the conductance spectrum shown in Fig. 13 to measure both $f_{\text {res }}$ and $Q$, which is then used to determine the dynamic viscosity of the investigated bitumen derivatives as described in $[22,25]$.

The results are shown in Fig. 14 for three types of bitumen derivative at various temperatures. The reference values are measured with a Brookfield DV3T viscometer. Basically, the results of both the 


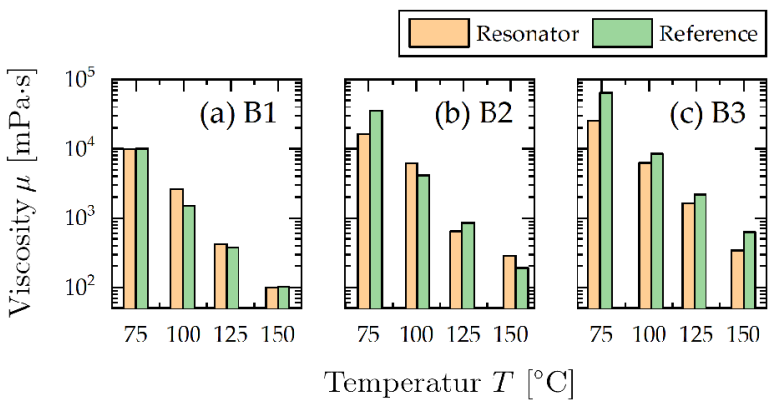

Fig. 14. Comparison of the measured dynamic viscosity values for the bitumen derivatives $\mathrm{B} 1-\mathrm{B} 3$ and the corresponding reference values at $T=75,100,125$ and $150^{\circ} \mathrm{C}$. @2019 IEEE. Reprinted, with permission, from [25]

MEMS sensor and the viscometer are in good agreement. With this cantilever based resonator, the viscosity can be measured up to a dynamic viscosity of $64000 \mathrm{mPas}$ with a moderate quality factor of 4 at $75^{\circ} \mathrm{C}$.

\section{Conclusions}

A promising class of mechanical modes is introduced, labeled as roof-tile shaped modes, and their benefit and potential for cantilever-type MEMS devices were presented. This class of 2dimensional mode features extremely high quality factors in liquid media. While high quality factors are often not necessary in applications in vacuum or air, they are of utmost importance for applications in liquids, especially when the latter are highly viscous. Due to the high damping in such environments, a low quality factor in air would result in no measureable signal after immersion. Besides the careful selection of the mode class, a high output sensor signal is achieved by matching the electrode design to the specific resonance mode shape.

These roof-tile shape resonator based sensors have been successfully operated and evaluated in three application scenarios: wine fermentation, detection of ferrous particles in liquids and viscosity measurements of bitumen. All in all, this broad range demonstrates the versatility and the potential of this technology platform for insitu real-time monitoring of physical quantities in liquids, while there are still interesting open questions such as energy loss by acoustic radiation and a theoretical model for the fluid structure interaction of 2D mode shapes immersed in liquids. These topics are the subject of ongoing and future investigations.

\section{Acknowledgements}

Open access funding provided by TU Wien (TUW). This work was partially supported by the Austrian Research Promotion Agency within the "Austrian COMET-Program" in the frame of K2 XTribology (project no. 824187 and 849109). This financial support is gratefully acknowledged. Furthermore, the authors thank Christoph Schneidhofer, Sherif Soliman and Mert-Ziya Erses for their support.

Publisher's Note Springer Nature remains neutral with regard to jurisdictional claims in published maps and institutional affiliations.

Open Access Dieser Artikel wird unter der Creative Commons Namensnennung 4.0 International Lizenz veröffentlicht, welche die Nutzung, Vervielfältigung, Bearbeitung, Verbreitung und Wiedergabe in jeglichem Medium und Format erlaubt, sofern Sie den/die ursprünglichen Autor(en) und die Quelle ordnungsgemäß nennen, einen Link zur Creative Commons Lizenz beifügen und angeben, ob Änderungen vorgenommen wurden. Die in diesem Artikel enthaltenen Bilder und sonstiges Drittmaterial unterliegen ebenfalls der genannten Creative Commons Lizenz, sofern sich aus der Abbildungslegende nichts anderes ergibt. Sofern das betreffende Material nicht unter der genannten Creative Commons Lizenz steht und die betreffende Handlung nicht nach gesetzlichen Vorschriften erlaubt ist, ist für die oben aufgeführten Weiterverwendungen des Materials die Einwilligung des jeweiligen Rechteinhabers einzuholen. Weitere Details zur Lizenz entnehmen Sie bitte der Lizenzinformation auf http://creativecommons.org/licenses/by/4.0/deed.de.

\section{References}

1. Manzaneque, T., et al. (2012): Characterization and simulation of the first extensional mode of rectangular micro-plates in liquid media. Appl. Phys. Lett., 101, 151904. https://doi.org/10.1063/1.4758470.

2. Riesch, C., et al. (2009): A suspended plate viscosity sensor featuring in-plane vibration and piezoresistive readout. J. Micromech. Microeng., 19, 075010. https:// doi.org/10.1088/0960-1317/19/7/075010.

3. Sell, J. K., Niedermayer, A. O. (2012): Jakoby B reactance-locked loop for driving resonant sensors. In 2012 IEEE I2MTC - proceedings of the international instrumentation and measurement technology conference (pp. 1113-1116). https:// doi.org/10.1109//2MTC.2012.6229687.

4. Blom, F. R., Bouwstra, S., Elwenspoek, M., Fluitman, J. H. J. (1992): Dependence of the quality factor of micromachined silicon beam resonators on pressure and geometry. J Vac Sci Technol B, 10(1), 19-26.

5. Ekinci, K. L., Yang, Y. T., Roukes, M. L. (2004): Ultimate limits to inertial mass sensing based upon nanoelectromechanical systems. J. Appl. Phys., 95(5), 2682-2689. https://doi.org/10.1063/1.1642738

6. Abadal, G., et al. (2001): Electromechanical model of a resonating nano-cantileverbased sensor for high-resolution and high-sensitivity mass detection. Nanotechnology, 12(2), 100-104. https://doi.org/10.1088/0957-4484/12/2/305.

7. Dufour, I., Fadel, L. (2003): Resonant microcantilever type chemical sensors: analytical modeling in view of optimization. Sens. Actuators B, Chem., 91(1-3), 353-361. https://doi.org/10.1016/S0925-4005(03)00110-2.

8. Ikehara, T., Lu, J., Konno, M., Maeda, R., Mihara, T. (2007): A high quality-factor silicon cantilever for a low detection-limit resonant mass sensor operated in air. J. Micromech. Microeng., 17(12), 2491-2494. https://doi.org/10.1088/0960-1317/17/12/015.

9. Johnson, B. N., Mutharasan, R. (2012): Biosensing using dynamic-mode cantilever sensors: a review. Biosens. Bioelectron., 32(1), 1-18. https://doi.org/10.1016/ j.bios.2011.10.054

10. Lavrik, N. V., Sepaniak, M. J., Datskos, P. G. (2004): Cantilever transducers as a platform for chemical and biological sensors. Rev. Sci. Instrum., 75(7), 2229-2253. https://doi.org/10.1063/1.1763252

11. Ziegler, C. (2004): Cantilever-based biosensors. Anal. Bioanal. Chem., 379(7-8), 946959. https://doi.org/10.1007/s00216-004-2694-y.

12. Song, Y., Bhushan, B. (2008): Atomic force microscopy dynamic modes: modeling and applications. J. Phys. Condens. Matter, 20(22), 225012. https://doi.org/ 10.1088/0953-8984/20/22/225012.

13. Beardslee, L. A., Josse, F., Heinrich, S. M., Dufour, I., Brand, O. (2012): Geometrical considerations for the design of liquid-phase biochemical sensors using a cantilever's fundamental in-plane mode. Sens. Actuators B, Chem., 164(1), 7-14. https://doi.org/10.1016/i.snb.2012.01.035.

14. Seo, J. H., Brand, O. (2008): High Q-factor in-plane-mode resonant microsensor platform for gaseous/liquid environment. J. Microelectromech. Syst., 17(2), 483-493. https://doi.org/10.1109/JMEMS.2008.916328.

15. Kucera, M., et al. (2014): Design-dependent performance of self-actuated and selfsensing piezoelectric-AIN cantilevers in liquid media oscillating in the fundamental in-plane bending mode. Sens. Actuators B, Chem., 200, 235-244. https:// doi.org/10.1016/j.snb.2014.04.048.

16. Kucera, M., Manzaneque, T., Sánchez-Rojas, J. L., Bittner, A., Schmid, U. (2013): Q-factor enhancement for self-actuated self-sensing piezoelectric MEMS resonators applying a lock-in driven feedback loop. J. Micromech. Microeng., 23(8), 085009. https://doi.org/10.1088/0960-1317/23/8/085009.

17. Kucera, M., et al. (2014): Characterization of a roof tile-shaped out-of-plane vibrational mode in aluminum-nitride-actuated self-sensing micro-resonators for liquid monitoring purposes. Appl. Phys. Lett., 104(23), 233501. https://doi.org/10.1063/ 1.4882177 .

18. Hernando, J., et al. (2010): Characterization and displacement control of low surfacestress AlN-based piezoelectric micro-resonators. Microsyst. Technol., 16(5), 855-861. https://doi.org/10.1007/s00542-009-1015-y.

19. Kucera, M., et al. (2015): Characterisation of multi roof tile-shaped out-of-plane vibrational modes in aluminium-nitride-actuated self-sensing micro-resonators in liquid media. Appl. Phys. Lett., 107(5), 053506. https://doi.org/10.1063/1.4928429.

20. Sanchez-Rojas, J. L., et al. (2010): Modal optimization and filtering in piezoelectric microplate resonators. J. Micromech. Microeng., 20(5), 055027. https://doi.org/ 10.1088/0960-1317/20/5/055027.

21. Pfusterschmied, G., et al. (2016): Roof tile-shaped modes in quasi free-free supported piezoelectric microplate resonators in high viscous fluids. Sens. Actuators B, Chem., 237, 999-1006. https://doi.org/10.1016/j.snb.2016.02.029. 
22. Pfusterschmied, G., et al. (2017): Potential of piezoelectric MEMS resonators for grape must fermentation monitoring. Micromachines, 8(7), 200. https:// doi.org/10.3390/mi8070200

23. Pfusterschmied, G., et al. (2015): Temperature dependent performance of piezoelectric MEMS resonators for viscosity and density determination of liquids. J. Micromech. Microeng., 25(10), 105014. https://doi.org/10.1088/0960-1317/25/10/105014

24. Patocka, F., et al. (2019): Piezoelectrically excited MEMS sensor with integrated plana coil for the detection of ferrous particles in liquids. Sens. Actuators B, Chem., 299, 126957. https://doi.org/10.1016/j.snb.2019.126957.

25. Pfusterschmied, G., et al. (2019): Sensing fluid properties of super high viscous liquids using non-conventional vibration modes in piezoelectrically excited MEMS resonators.

\section{Authors}

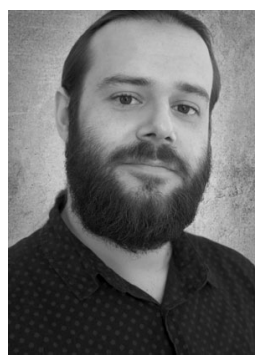

\section{Michael Schneider}

studied in physics at the Karlsruhe Institute of Technology 2003-2009. He performed his diploma work at the Forschungszentrum Karlsruhe on the measurement of Lorentz angles in highly irradiated silicon strip detectors for high energy collider applications such as the large hadron collider at CERN. He finished his studies in 2009 and started his PhD thesis on the optimization of ultra-thin aluminum nitride films for actuation and sensing applications in micro electromechanical systems at the department of Microsystems Technology at TU Wien. He received his PhD in 2014 and is currently working as postdoc on advanced materials like PVDF and doped aluminum nitride as well as MEMS devices based on piezoelectric thin films.

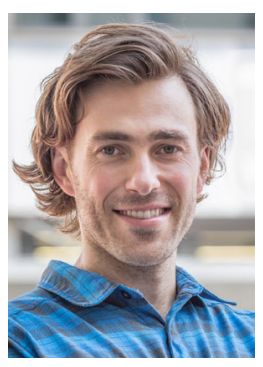

\section{Georg Pfusterschmied}

studied material science at TU Wien and received his Dipl. Ing. (M.Sc.) degree in 2013 From 2014-2018 he worked in the field of piezoelectric MEMS resonators for liquid sensing applications at TU Wien and was awarded a PhD degree in 2018. Since May 2018 he continues his research as a post-doc at the Institute of Sensor and Actuator Systems at TU Wien.

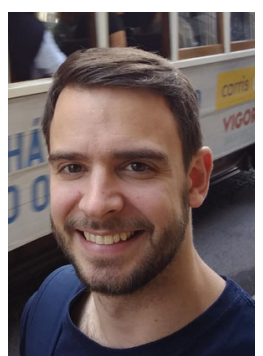

\section{Florian Patocka}

received his B.Sc and his Dipl.-Ing. (M.Sc.) degree at TU Wien in 2013 and 2015, respectively. He joined the Institute of Sensor and Actuator Systems at TU Wien as a Ph.D. student where he investigates the application of MEMS devices for mass sensing in liquids.
In Proceedings of the IEEE international conference on micro electro mechanical systems (MEMS) (pp. 735-738). https://doi.org/10.1109/MEMSYS.2019.8870897.

26. Jensen, J., Farina, M., Zuccheri, G., Grange, W., Hegner, M. (2012): Quantitative, label-free detection of the aggregation of $\alpha$-synuclein using microcantilever arrays operated in a liquid environment. J. Sens., 2012, 874086. https://doi.org/ 10.1155/2012/874086

27. Tseng, Y. C., Chang, J. S., Lin, S., Chao, S. D., Liu, C. H. (2012): 3,4-Methylenedioxymethylamphetamine detection using a microcantilever-based biosensor. Sens. Actuators A, Phys., 182, 163-167. https://doi.org/10.1016/j.sna.2012.05.036.

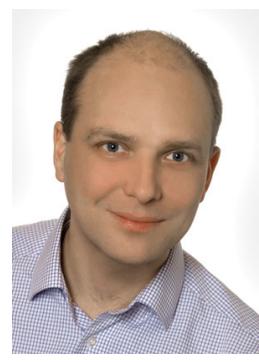

\section{Ulrich Schmid}

was born in Munich, Germany, in 1972. He started studies in physics and mathematics at the University of Kassel in 1992. In 1995, he spent 6 months at the Transport Group in the Physics Department, University of Nottingham, UK, to gain experience in wide band gap semiconductor physics. He performed his diploma work at the research laboratories of the Daimler-Benz AG (now Daimler AG) on the electrical characterization of silicon carbide $(6 \mathrm{H}-\mathrm{SiC})$ junction field effect transistors at high temperatures. During this time, he also investigated metal-oxide-semiconductor (MOSiC) based structures, such as gate controlled diodes, MOSFETs, and integrated circuits for harsh environment applications. He finished his studies in 1998 at the University of Frankfurt/Main, Germany. In 1999, he joined the research laboratories of DaimlerChrysler AG (now Airbus Group) in Ottobrunn/Munich, Germany. He developed a robust flow sensor for high-pressure automotive applications and received his Ph.D. degree in 2003 from the Technische Universität München, Germany. From 2003 to 2008, he was Post-doc at the Chair of Micromechanics, Microfluidics/Microactuators at Saarland University. Since October 2008, he is full professor for Microsystems Technology at TU Wien heading since 2012 the Institute of Sensor and Actuator Systems. U. Schmid has authored or co-authored more than 400 peerreviewed publications in journals and international conferences and holds more than 50 different granted patent families. 